\title{
Carbon Monoxide Poisoning In Children: Which Cases Should Receive Advanced Cardiologic Evaluation?
}

\author{
Funda Kurt (Corresponding author) \\ Division of Pediatric Emergency Medicine, Ankara City Hospital, Ankara, Turkey \\ E-mail: drfundakurt@gmail.com \\ Ezgi Hasbek \\ Department of Pediatrics, Ankara Child Health and Diseases Hematology Oncology Training and \\ Research Hospital, University of Health Sciences, Ankara, Turkey \\ E-mail: ezoibicek@yahoo.com \\ Cuneyt Gursoy \\ Division of Pediatric Emergency Medicine, Ankara City Hospital, Ankara, Turkey \\ E-mail: d.tanilkurtmail.com \\ Lutfiye Tuba Hanci \\ Diskapi Yildirim Beyazit Training and Research Hospital Biochemistry Department, Ankara, Turkey \\ E-mail: tubahanci@gmail.com \\ Ibrahim Ilker Cetin \\ Division of Pediatric Cardiology, Ankara City Hospital, Ankara, Turkey \\ E-mail: iicetin@hotmail.com \\ Halil Ibrahim Yakut \\ Division of Pediatric Emergency Medicine, Ankara City Hospital, Ankara, Turkey \\ E-mail: dribrahimyakut@gmail.com \\ Emine Dibek Misirlioglu \\ Division of Pediatric Emergency Medicine, Ankara City Hospital, Ankara, Turkey \\ E-mail: edibekm@yahoo.com
}

\begin{abstract}
Aim: This study aimed to determine the relationship between carboxy-hemoglobin ( $\mathrm{COHb})$ and neurological and cardiac effects in patients admitted to our pediatric emergency department with $\mathrm{CO}$ poisoning and identify the patients who require advanced cardiologic evaluation.

Materials and methods: Between January 2013 and January 2016, 412 children with carbon monoxide poisoning admitted to our hospital were evaluated retrospectively.

Results: The incidence of COHb, lactate, CK-MB (creatinine kinase-myocardial band), troponin I and BNP (B-type natriuretic peptide) levels were higher in patients with who had altered state of consciousness $(p<0.001, \mathrm{p}<0.001, p<0.001, p<0.001, p<0.001$, respectively). Hypotension was found in $8(27.6 \%)$ of $29(7 \%)$ patients with a Glasgow coma scale (GCS) score of 14 and below. BNP and troponin I levels were found to be high in patients with hypotension. For cardiac involvement, the sensitivity and specificity of $\mathrm{COHb} 20.1 \%$ value were $50.0 \%$ and $72.4 \%$, respectively; and lactate at 2.95 $\mathrm{mmol} / \mathrm{L}$ had a sensitivity and specificity value of $41.2 \%$ and $82.4 \%$ respectively.
\end{abstract}

Conclusion: High BNP levels may be useful in determining the severity of intoxication in patients with altered state of consciousness. Cardiological evaluation should be performed in patients with a GCS score of 14 or lower or hypotension.

Key words: Child, carbon monoxide, cardiac finding, neurological finding

Special Issue of Health Sciences

DOI: $10.7176 /$ JSTR/6-03-29

237 I P a g e

www.iiste.org 


\section{Introduction}

$\mathrm{CO}$ is a toxic gas produced by partial combustion of carbon-containing materials such as gasoline, propane, kerosene, coal.(1-3) Inhalation of fire smoke is responsible for most of the CO poisoning. In the United States, CO poisoning due to causes other than fire smoke is the leading cause of poisoning deaths in the country, with 50,000 emergency service applications and 1200 deaths per year (4-6).

Childhood metabolic rate and oxygen demand are high; therefore, this age group is more sensitive to $\mathrm{CO}$ poisoning (7). CO intoxication, where the toxic effect is caused by tissue hypoxia, affects all tissues, but the toxic effect is more pronounced in organs with high oxygen consumption such as the brain and heart $(8,9)$.

CO intoxication can cause varying degrees of mental status changes, headache, tremor, ataxia, neck stiffness, neurological findings that may end up with coma (7). Impaired consciousness occurs via different mechanisms. The formation of $\mathrm{COHb}$ causes tissue hypoxia and cell death. $\mathrm{CO}$ binds directly to intracellular proteins (myoglobin, cytochrome, guanylate cyclase) and causes direct cell damage. It has been demonstrated in animal models that cGMP is increased by guanylate cyclase stimulation, and it causes cerebral vasodilatation and, consequently, loss of consciousness (10). Another effect of carbon monoxide that causes loss of consciousness is that it increases the blood level of NO (Nitric oxide) and causes cerebral vasodilatation (11). In cardiac involvement, it may cause myocardial ischemia presenting with electrocardiographic changes (ST-segment and $\mathrm{T}$ wave changes, sinus tachycardia, premature contractions, low voltage), echocardiographic changes (ventricular dysfunction, pathological valve failure), and elevation of cardiac markers (troponin I, CK-MB) $(8,12)$.

In this study, we aimed to determine the relationship between $\mathrm{COHb}$ and cardiac and neurological effects of patients presenting to the pediatric emergency department with carbon monoxide poisoning and to determine the patients that require further cardiologic evaluation.

\section{Methods}

Patients who applied to the pediatric emergency department of Ankara Pediatric Hematology-Oncology Training and Research Hospital between January 2013 and January 2016 and received the code 'T58Toxic Effect of Carbon monoxide' according to the International Disease Classification Version 10 (ICD10) coding system were included in the study. There were 485 cases with a T58 diagnosis code between the study dates. Seventy-three cases with incorrect diagnostic code and missing information were not included in the study. The study was approved by the local ethics committee (2016-025).

Age, gender, date of admission, duration of admission after exposure, presence of other poisoning cases in the family, altered state of consciousness, GCS score, blood gas, electrocardiography (ECG), echocardiography (ECHO), cardiac marker results (troponin I, CK-MB), emergency service observation, hospitalization in pediatric ward or pediatric intensive care unit, hospitalization duration (day), hyperbaric oxygen (HBO) treatment, and the number of sessions they received were recorded for each case.

ECG was performed on patients who had pathological cardiac findings during the physical examination at the time of application. According to the ECG results, echo was performed. In the presence of ventricular dysfunction or pathological valve failure, cardiac markers were evaluated. Also, BNP was examined in patients who had low blood pressure or ventricular dysfunction, which was detected in the echo.

In patients with high cardiac markers at the time of application, cardiac markers were re-evaluated at 46 hour intervals. Sinus tachycardia was accepted when resting heart rate was above normal for age. Elevated cardiac markers were considered as diagnostic criteria for myocardial injury. For systolic blood pressure, values below $70 \mathrm{mmHg}$ for between 1 month-1 year; 70+ (2x years) between 1-10 years, 90 $\mathrm{mmHg}$ for age ten and older were considered as hypotension.

All patients were treated with $100 \%$ oxygen (normobaric oxygen $=\mathrm{NBO}$ ) with a reservoir mask. In patients with carbon monoxide poisoning, the treatment was considered efficient when $\mathrm{COHb}$ value decreased to less than 5\% after 6-8 hours, and symptoms showed complete regression. Hyperbaric oxygen therapy (HBO) was applied to patients who had a loss of consciousness, new neurological deficit or altered state of consciousness, ischemic changes on ECG, and COHb level > 25\%. Hyperbaric oxygen is $100 \%$ oxygen at 5 atm pressure that is given to patients in a chamber for 90 minutes.

Cardiac markers were studied on ADVIA CENTAUR CP (Siemens, Germany) before October 2014, and the reference ranges were; troponin I: 0-0.06 ng/ml, CK-MB: 0-5 ng/ml, BNP: 0-100 pg/ml. After October 2014, cardiac markers were studied on Beckman Coulter ACCESS 2 (Beckman Coulter, USA). The reference ranges for this device were as follows; troponin I: 0-0.04 ng/ml, CK-MB: 0-5 ng/ml, BNP: $0-100 \mathrm{pg} / \mathrm{ml}$. 


\section{Statistical analysis}

Statistical analysis was performed using the SPSS (Statistical Package for Social Sciences) for Windows 20 (SPSS Inc., Chicago, IL, USA) program. The normality distribution of the data was evaluated with the Kolmogorov-Smirnov normality tests. Normally distributed variables were expressed in mean $\pm \mathrm{SD}$, while abnormally distributed variables were expressed in median (Interquartile range). The MannWhitney U-test was used to compare abnormally distributed variables between two groups. The Pearson chi-square test was used to compare categorical variables. A $p$-value of $<0.05$ was considered statistically significant. Regression analysis was performed to determine whether ECG, ECHO, CK-MB, troponin I, lactate, and $\mathrm{COHb}$ parameters were safe for cardiac involvement. Diagnostic statistics were given for ROC curves and selected cutoff values.

\section{Results}

During the study period, 412 cases included in the study. The median (IQR) age was 113.5 (2- 215) months, and $194(47.1 \%)$ were male. The mean $\mathrm{COHb}$ level was $14.5 \pm 9.7 \%$. The most common source of carbon monoxide was natural gas (54.6\%). Seventy-seven (18.7\%) of the patients had received oxygen treatment before admission to our hospital. The median time to admission to the hospital after poisoning (min-max) was 4.3 hours (10 minutes- 48 hours). Poisoning was found to be cumulative in $375(91.0 \%)$ cases. One of the cases $(0.2 \%)$ was a suicide (Table 1$)$.

Eighty-four (20.4\%) patients applied with an altered state of consciousness. Hypotension was detected in $8(27.6 \%)$ out of $29(7.0 \%)$ patients with GCS score of 14 and below; BNP and troponin I levels were found to be high in patients with hypotension. Of the 385 (93.4\%) ECG performed patients, 94 (24.4\%) had sinus tachycardia, $3(0.8 \%)$ had ST-T changes, $4(0.1 \%)$ had right bundle branch block, and $1(0.3 \%)$ had ventricular tachycardia. Of 39 (9.5\%) patients who underwent ECHO, $5(12.8 \%)$ had mild mitral insufficiency, $1(2.6 \%)$ had mild aortic insufficiency, and $1(2.6 \%)$ had left ventricular dysfunction. In a patient with $\mathrm{CO}$ intoxication due to fire, who was found unconscious at home and sent to our hospital for intensive care after a cardiopulmonary arrest, VT was detected in ECG, and left ventricular dysfunction was present in the ECHO examination (Table 2). Cardiac enzyme levels were measured in 308 patients (74.8\%). The mean troponin I was $0.1 \pm 0.6(0.1-5.5) \mathrm{ng} / \mathrm{ml}$.

Table 1. Characteristics of patients with carbon monoxide poisoning $(n=412)$.

\begin{tabular}{|c|c|}
\hline Characteristics & n $(\%)$ \\
\hline Age (month) ${ }^{\mathrm{a}}$ & $113.5(2-215)$ \\
\hline Gender & \\
\hline Male & $194(47.1)$ \\
\hline Female & $218(52.9)$ \\
\hline COHb level $(\%)^{*}$ & $14.5 \pm 9.7(0.5-52)$ \\
\hline Source of $\mathrm{CO}$ poisoning & \\
\hline Natural gas & $225(54.6)$ \\
\hline Coal stove & 163 (37.6) \\
\hline Fire & $23(5.6)$ \\
\hline Waterpipe & $1(0.2)$ \\
\hline Number of people poisoned in the family & \\
\hline $\begin{array}{r}\geq 2 \\
1\end{array}$ & $\begin{array}{l}375(91.0) \\
39(9.0)\end{array}$ \\
\hline $\begin{array}{l}\text { The median time to admission to the hospital after poisoning (hour) } \\
1 \mathrm{hr} \\
2 \mathrm{hr}\end{array}$ & $\begin{array}{l}4.3(1-5) \\
61(38.6) \\
227(55.1)\end{array}$ \\
\hline $\begin{array}{l}\text { Time of visit } \\
\text { 08:00 AM to 16:30 PM } \\
\text { 16:31 PM to 11:59 PM } \\
\text { Midnight to 07:59 AM }\end{array}$ & $\begin{array}{l}159(38.6) \\
101(24.5) \\
152(36.9)\end{array}$ \\
\hline Death & $1(0.2)$ \\
\hline
\end{tabular}

COHb: carboxy-hemoglobin.

${ }^{a}$ median (IQR: Interquartile Range), ${ }^{b}$ Data represents mean \pm SD (range). 
$391(95.0 \%)$ of the cases were observed in emergency unit, $5(1.2 \%)$ were in the pediatric intensive care unit, and $16(3.8 \%)$ were hospitalized in the pediatric ward. The hospitalization duration of the patients who were followed up in the ward was between 1-7 days. The median (IQR) duration of emergency observation was 8.0 (4.0- 8.0) hours. One patient who was poisoned due to fire was admitted to our hospital with GCS 3, he was intubated at the time of admission and died three days later. Eighty-two $(19.9 \%)$ of the patients received hyperbaric oxygen therapy (Table 2 ).

Table 2. Clinical characteristics of patients with carbon monoxide poisoning.

\begin{tabular}{lc}
\hline & $\mathbf{n}(\%)$ \\
\hline History of altered level of consciousness & $84(20.4)$ \\
GCS ( $\leq$ 14) & $29(7)$ \\
ECG & $385(93.4)$ \\
Normal & $283(73.5)$ \\
Sinus tachycardia & $94(24.4)$ \\
ST-T wave changes & $3(0.8)$ \\
Right bundle branch block & $4(1.0)$ \\
Ventricular tachycardia & $1(0.3)$ \\
ECHO & $39(9.5)$ \\
Normal & $29(82.0)$ \\
Mild mitral insufficiency & $5(12.8)$ \\
Mild aort insufficiency & $1(2.6)$ \\
Left ventricular dysfunction & $1(2.6)$ \\
Admission & \\
Emergency Observation Unit & $391(95.0)$ \\
Pediatric Ward & $16(3.8)$ \\
PICU & $5(1.2)$ \\
Emergency Service Observation Time (hour) & a \\
HBO2 therapy & $8,0(4.0-8.0)$ \\
HBO2 therapy indication & $82(19.9)$ \\
High COHb level & \\
Loss of consciousness & \\
Loss of consciousness and myocardial ischemia & $40(48.8)$ \\
Myocardial ischemia & $39(47.6)$ \\
HBO treatment number & $2(2.4)$ \\
1 & $1(1.2)$ \\
2 3 & \\
\hline
\end{tabular}

GCS:Glaskow Coma Scale; ECG: electrocardiogram; ECHO: echocardiogram; PICU: Pediatric Intensive Care Unit; $\mathrm{HBO} 2$ :hyperbaric oxygen; $\mathrm{COHb}$ : carboxy-hemoglobin.

${ }^{a}$ median (IQR: Interquartile Range)

Lactate, $\mathrm{COHb}$, troponin I, CK-MB, and pro-BNP levels were higher in patients who had altered state of consciousness compared to the patients who had not $(p<0.001, p<0.001, p<0.001, p<0.001, p<$ 0.001 , respectively) (Table 3).

There was a positive correlation between $\mathrm{COHb}$ level and lactate and CK-MB $(\mathrm{r}=0.4, p<0.001$ and $\mathrm{r}$ $=0.2 ; p<0.001)$. BNP levels were positively correlated with lactate and CK-MB $(\mathrm{r}=0.5, p<0.05$ and $\mathrm{r}=0.4 ; p<0.05)$.

The median (IQR) age of patients with high-level cardiac markers and normal levels were 100.5 (32.3150.0) and 117.0 (73.0-132.3) months, respectively; patients with high cardiac marker levels were found to be in the younger age group $(p=0.034)$. No significant difference was found between the patients with high-level cardiac markers and the normal range ones in terms of gender and BNP level.

When regression analysis was performed for cardiac involvement, of the parameters ECG, ECHO, CK$\mathrm{MB}$, troponin I, lactate and $\mathrm{COHb}$, it was concluded that only troponin I and CK-MB values were "reliable" in determining the cardiac involvement ( $p<0.001, p<0.001$, respectively).

The optimal cutoff values of $\mathrm{COHb}$ and lactate were estimated by ROC (Receiver Operating Characteristic) curves (Figures 1 and 2). For showing the cardiac involvement via the ROC analysis method, the area under the curve (AUC) values for $\mathrm{COHb}$ and lactate levels were found to be 0.64 (95\% 
confidence interval, CI; 0.569-0.711); 0.665 (95\% confidence interval, CI; 0.568-0.733), respectively. Lactate and $\mathrm{COHb}$ were found to be statistically significant in determining cardiac involvement $(p<$ $0.001, p<0.001$, respectively).

Table 3. Clinical features in patients with and without altered state of consciousness.

\begin{tabular}{|c|c|c|c|}
\hline \multicolumn{4}{|c|}{ History of altered state of consciousness } \\
\hline & $\begin{array}{c}\text { yes } \\
(\mathrm{n}: 84)\end{array}$ & $\begin{array}{c}\text { no } \\
\text { (n:328) }\end{array}$ & $p$-Value \\
\hline Age (month) ${ }^{a}$ & $119.5(51.5-164.8)$ & $112.0(59.0-158.8)$ & 0.434 \\
\hline Male (n, \%) & $38(45.2)$ & $156(47.6)$ & 0.704 \\
\hline pH & $\begin{array}{c}7.38 \pm 0.6 \\
(7.18-7.52)\end{array}$ & $\begin{array}{l}7.39 \pm 0.5 \\
(7.1-7.63)\end{array}$ & 0.467 \\
\hline Laktat $(\mathbf{m m o l} / \mathrm{L})^{b}$ & $\begin{array}{c}3 \pm 2.3 \\
(0.8-16)\end{array}$ & $\begin{array}{c}2.1 \pm 1 \\
(0.7-7.5)\end{array}$ & $<0.001$ \\
\hline COHb level $(\%)^{b}$ & $\begin{array}{c}20 \pm 11.2 \\
(0.8-52)\end{array}$ & $\begin{array}{l}13 \pm 8.7 \\
(0.5-45)\end{array}$ & $<0.001$ \\
\hline Troponin-I (ng/ml) ${ }^{b}$ & $\begin{array}{c}0.36 \pm 1.2 \\
(0.01-5.5)\end{array}$ & $\begin{array}{l}0.04 \pm 0.1 \\
(0.01-0.9)\end{array}$ & $<0.01$ \\
\hline CK-MB (ng/ml) ${ }^{b}$ & $\begin{array}{c}21.1 \pm 34.5 \\
(1-284)\end{array}$ & $\begin{array}{c}16 \pm 14.7 \\
(0.04-102)\end{array}$ & $<0.01$ \\
\hline 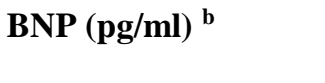 & $\begin{array}{c}143.7 \pm 200.6 \\
(30-691)\end{array}$ & $\begin{array}{c}29.1 \pm 23.3 \\
(5.4-77)\end{array}$ & $<0.01$ \\
\hline
\end{tabular}

COHb: carboxy-hemoglobin; CK-MB: creatine kinase miyocardial band; BNP: brain natriuretic peptide.

${ }^{\mathrm{a}}$ median (IQR: Interquartile Range) ; ${ }^{\mathrm{b}}$ Data represents mean $\pm \mathrm{SD}$ (range).

Table 4. Coordinates of Curve for $\mathrm{COHb}$ and Lactate Levels.

\begin{tabular}{|c|c|c|}
\hline & Sensitivity-\% & Specificity-\% \\
\hline \multicolumn{3}{|l|}{ COHb (\%) } \\
\hline 10.1 & 88.4 & 23.1 \\
\hline 15.1 & 61.6 & 51.6 \\
\hline 20.1 & 50.0 & 72.4 \\
\hline 25.0 & 36.0 & 86.9 \\
\hline 30.1 & 20.9 & 95.5 \\
\hline \multicolumn{3}{|l|}{ Lactate (mmol/L) } \\
\hline 2.05 & 74.1 & 47.5 \\
\hline 2.45 & 55.3 & 67.4 \\
\hline 2.95 & 41.2 & 82.4 \\
\hline 3.45 & 29.4 & 88.2 \\
\hline 3.95 & 22.4 & 91.9 \\
\hline
\end{tabular}

Table 4 shows the specificity and sensitivity rates at different cutoff values for $\mathrm{COHb}$ and lactate levels. For cardiac involvement, for the value of $20.1 \% \mathrm{COHb}$, the sensitivity and specificity values were $50.0 \%$ and $72.4 \%$, respectively; for lactate value of $2.95 \mathrm{mmol} / \mathrm{L}$, the sensitivity and specificity values were $41.2 \%$ and $82.4 \%$ respectively.

Tables 5 and 6 provide diagnostic statistics for the determined cutoff values for $\mathrm{COHb}$ and lactate $(\mathrm{COHb}$ $20.1 \%$, lactate $2.95 \mathrm{mmol} / \mathrm{L}$ ). The positive predictive value of $\mathrm{COHb} 20.1 \%$ cutoff value was $41.35 \%$, and the negative predictive value was $78.92 \%$; The positive predictive value of lactate $2.95 \mathrm{mmol} / \mathrm{L}$ was $47.30 \%$, and the negative predictive value was $78.21 \%$. 
Table 5. Diagnostic statistics for $20.1 \%$ COHb level.

\begin{tabular}{lll}
\hline Statistics & Value & $\mathbf{9 5 \%}$ CI \\
\hline Sensitivity & $50.0 \%$ & $39.02 \%$ to $60.98 \%$ \\
Specificity & $72.4 \%$ & $66.15 \%$ to $78.28 \%$ \\
Positive Likelihood Ratio & 1.82 & 1.35 to 2.46 \\
Negative Likelihood Ratio & 0.69 & 0.55 to 0.86 \\
Positive Predictive Value & $41.35 \%$ & $34.29 \%$ to $48.77 \%$ \\
Negative Predictive Value & $78.92 \%$ & $74.91 \%$ to $82.44 \%$ \\
\hline
\end{tabular}

COHb: carboxy-hemoglobin

Table 6. Diagnostic statistics for lactate $2.95(\mathrm{mmol} / \mathrm{L})$ level.

\begin{tabular}{lcc}
\hline Statistics & Value & 95\% CI \\
\hline Sensitivity & $41.2 \%$ & $30.22 \%$ to $51.83 \%$ \\
Specificity & $82.4 \%$ & $76.78 \%$ to $87.20 \%$ \\
Positive Likelihood Ratio & 2.32 & 1.58 to 3.40 \\
Negative Likelihood Ratio & 0.72 & 0.60 to 0.87 \\
Positive Predictive Value & $47.30 \%$ & $37.97 \%$ to $56.81 \%$ \\
Negative Predictive Value & $78.21 \%$ & $74.88 \%$ to $81.20 \%$ \\
\hline
\end{tabular}

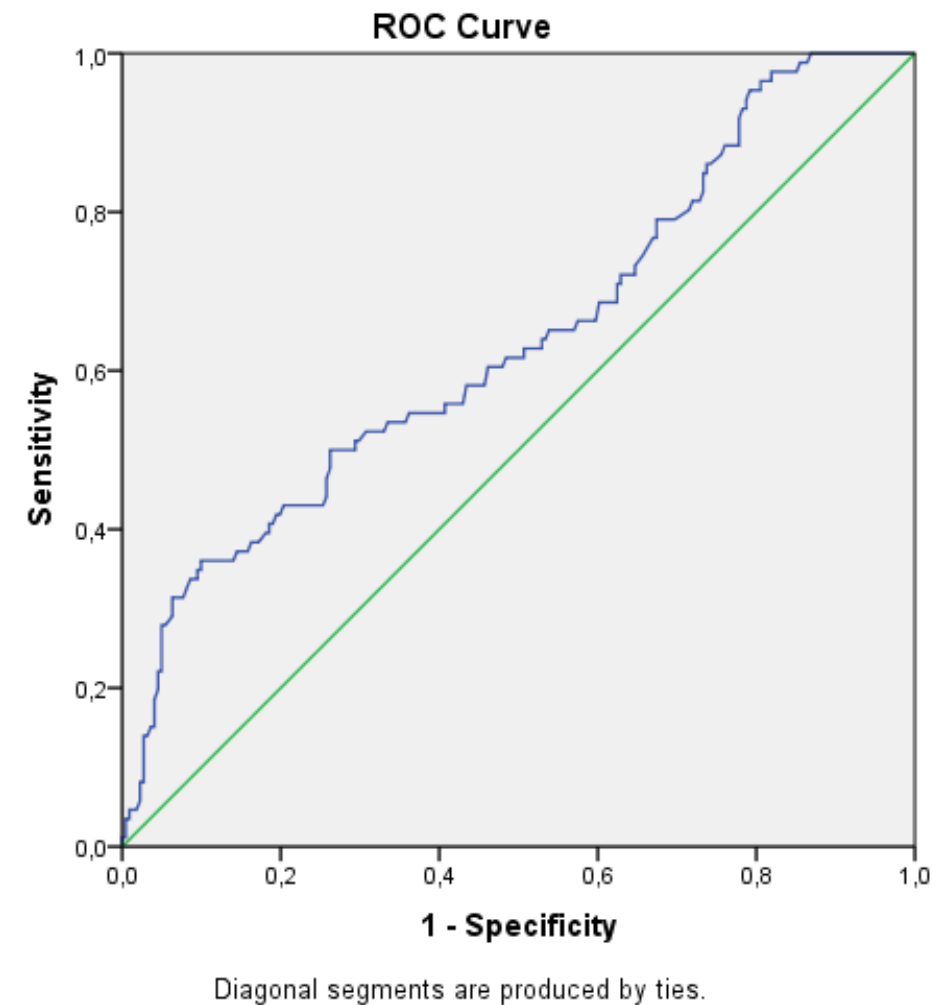

Figure 1. The ROC (Receiver Operating Characteristic) curve analysis for carboxy-hemoglobin $(\mathrm{COHb})$ level. The area under the curve was $0.64 \pm 0.36$ for $\mathrm{COHb}$. The difference between areas was significant (95\% confidence interval, CI; 0.569-0.711) $(\mathrm{p}<0.001)$. 


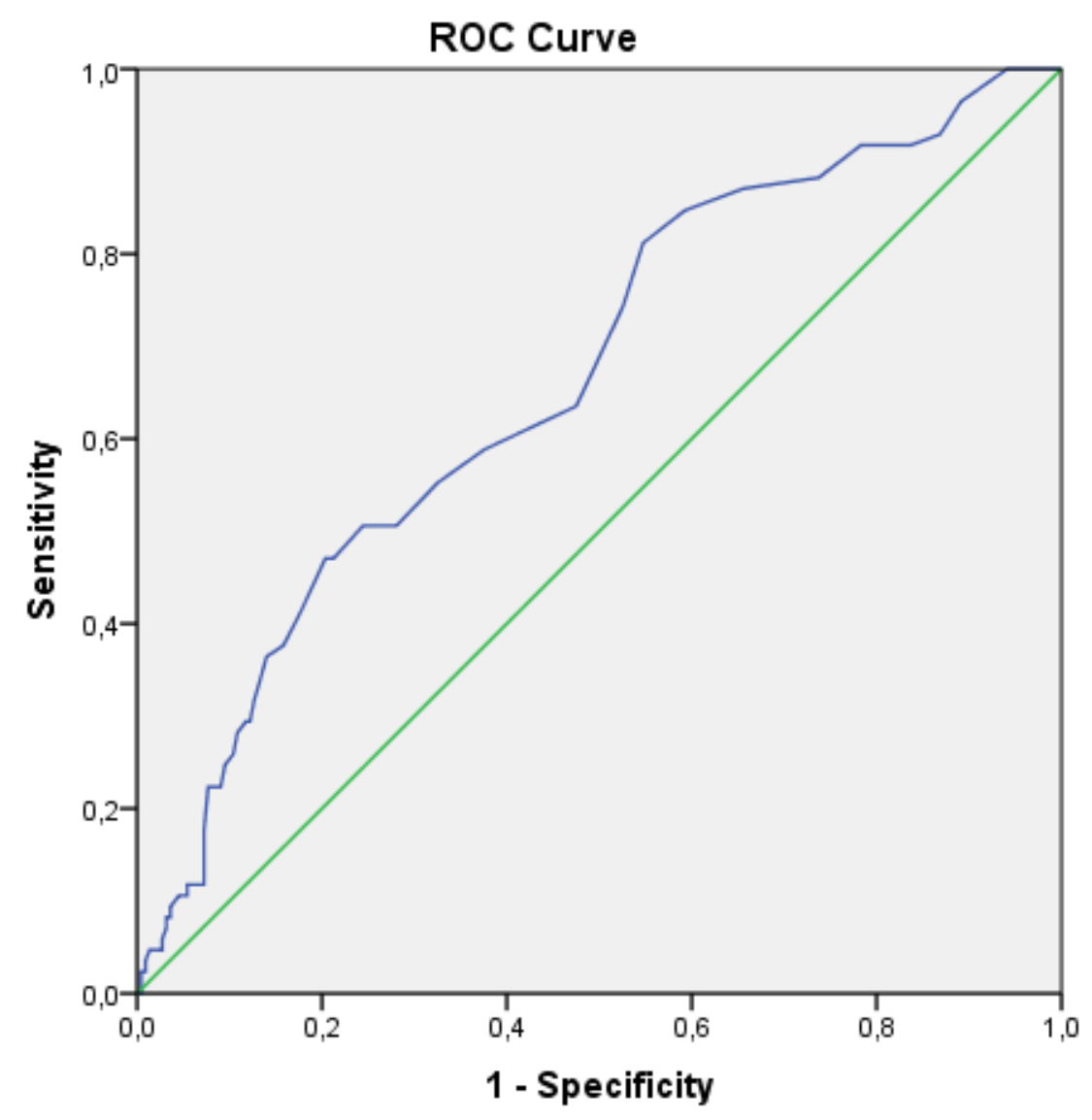

Diagonal segments are produced by ties.

Figure 2. The ROC (Receiver Operating Characteristic) curve analysis for lactate level. The area under the curve was $0.665 \pm 0.34$ for lactate. The difference between areas was significant $(95 \%$ confidence interval, CI; 0.568-0.733) $(\mathrm{p}<0.001)$.

\section{Discussion}

In our study, BNP levels of patients who had an altered state of consciousness were higher than patients had not. Patients who had hypotension and had a GCS score of 14 and below found to have higher BNP and troponin I levels. It was found that cardiac markers were higher in the younger age group, troponin $\mathrm{I}$ and CK-MB values were "reliable" in determining cardiac involvement, and lactate and $\mathrm{COHb}$ were statistically significant in determining cardiac involvement.

Carbon monoxide poisoning can be seen for different reasons depending on the region and sociocultural factors.(13) Some studies have reported stove poisoning as the most common source of poisoning, $(8$, 13-15) and some as natural gas poisoning (16-18). In the last 20 years, the use of natural gas as a fuel has become widespread in Ankara. In our study, it was determined that natural gas poisoning was the most common cause $(54.6 \%)$. Keleş et al.(19) reported that cases of collective poisoning were frequently encountered due to family members sleeping in the same room. In our study, it was determined that $91 \%$ of the cases were intoxicated collectively. This result was as expected since carbon monoxide poisoning was related to the heating system in the shared living habitat (Table 1).

In carbon monoxide poisoning, tissue hypoxia, which is the result of deterioration in mitochondrial oxidative capacity, causes lactate increase. In the situations of loss of consciousness or coma, which are considered to be the sign of severe $\mathrm{CO}$ poisoning lactate levels are found to be high (20-22). In some studies, positive correlation was found between $\mathrm{COHb}$ and lactate, and it was reported that the lactate level could be used to indicate the severity of CO intoxication $(8,14,23)$. It has been shown in studies that the severity of clinical findings, especially neurological findings, was associated with the $\mathrm{COHb}$ level (23-25). A significant correlation was found between the loss of consciousness and $\mathrm{COHb}$ and 
lactate levels $(3,8,23)$. In our study, we showed a positive correlation between $\mathrm{COHb}$ and lactate $(\mathrm{r}=$ $0.4, p<0.001)$. The mean $\mathrm{COHb}$ and lactate levels of the patients with neurological findings were significantly higher than those without the neurological findings $(p<0.001$ and $p<0.001$, respectively). This condition is thought to be due to tissue hypoxia and cerebral ischemia.

In some studies CK-MB, Troponin I levels, which indicate ischemic myocardial damage were significantly higher in the presence of neurological symptoms $(12,23,26)$. We also found that troponin I, CK-MB levels of our patients with altered state of consciousness were significantly higher than those without. We think that cardiac enzyme levels may be useful in patients with neurological symptoms.

BNP is an important marker that is used to show left ventricular dysfunction and heart failure. Due to the increase in ventricular tension and the effect of various neurohormonal factors, myositis release Pro-BNP pulsatilly into the circulation, where it is converted to active BNP and inactive NT-Pro-BNP by proteolysis $(27,28)$. Other than the heart tissue, BNP can be released from different parts of the brain (thalamus, hypothalamus, cerebral cortex, brain stem, and cerebellum). It has been shown in recent studies that hypoxia alone induces BNP release, even without mechanical stress in the heart (29). This situation may indicate the relationship between BNP and neurological outcomes. In the study of Moon et al.(9) increased serum BNP level was correlated with long-term poor neurological outcome in acute $\mathrm{CO}$ intoxication due to coal. In the literature, there was no study showing the effect of the BNP level on the evaluation of acute neurological status in $\mathrm{CO}$ intoxication.

In our study, BNP levels in patients with impaired consciousness were found to be significantly higher than patients without consciousness change. We think that BNP increases in CO intoxication due to hypoxemia and may be useful in determining the severity of intoxication.

Some studies have shown a positive correlation between COHb and CK-MB (1, 3, 23). Besli et al.(8) found that the mean CK-MB levels of patients who had lactate increase were significantly higher than those with normal lactate levels. Cervellin et al.(30) reported a positive correlation between lactate and troponin. Damlapınar et al.(23) reported that $\mathrm{COHb}$ was positively correlated with $\mathrm{CK}-\mathrm{MB}$ and lactate had a positive correlation with CK-MB, troponin I. Similarly, we showed a positive correlation between $\mathrm{COHb}$ and $\mathrm{CK}-\mathrm{MB}$ and lactate and CK-MB, and troponin $\mathrm{I}(\mathrm{r}=0.2, p<0.001$ and $\mathrm{r}=0.2, p<0.001$, respectively). It is thought that the lactate level can be used as an indicator of ischemic myocardial damage.

In the study of Teksam et al.(18) 30.5\% of the sample had sinus tachycardia, and this finding was thought to be developed as a response to systemic hypoxia and was used in the detection of myocardial injury. Gandini et al.(31) reported that sinus tachycardia is a common finding in children with CO intoxication, but there is no specific evidence of CO-related cardiac damage; and added that gallop rhythm had higher predictivity of abnormal cardiac function. Although sinus tachycardia was common in our study, it was not used to show myocardial damage, and none of the patients had gallop rhythm.

Myocardial depression, peripheral vasodilatation, and ventricular dysrhythmia have been found to cause hypotension in animal models of carbon monoxide poisoning (32). Hypotension and hypoxia were shown to be effective in detecting neurological damage $(32,33)$. Hypotension is common in cases of severe CO intoxication and in the presence of neurological symptoms. Damlapınar et al.(23) found hypotension in 9.7\% of the patients; and reported a positive correlation between hypotension and troponin I and CK$\mathrm{MB}$, and hypotension was more common in patients with severe $\mathrm{CO}$ intoxication and neurological symptoms. In the study of Tekşam et al.(18) hypotension was observed in $6.8 \%$ of the patients, and $66.6 \%$ of the patients with hypotension had a GCS score of 14 or less. In our study, there were $29(7 \%)$ patients with GCS of 14 or below 14, and hypotension was found in 8 (27.6\%) of these patients. BNP and Troponin-I levels were found to be high in patients with hypotension. Similar to previous studies, the relationship between low GCS and hypotension is thought to show a close relationship between myocardial damage and neurological abnormalities $(18,32)$. Cardiac enzyme monitoring is recommended in patients with hypotension.

It is often challenging to detect CO-dependent cardiac injury in pediatric patients. Abnormal ECG findings that are seen in adult population groups such as ST and T wave changes in the presence of myocardial injury, but children may not reveal those signs; therefore, it is recommended to monitor myocardial damage in children even without abnormal ECG findings. Satran et al.(12) found a $37 \%$ frequency of cardiac damage in adults with moderate-severe $\mathrm{CO}$ intoxication and reported that cardiac enzyme elevation was associated with CO levels. They suggested that patients with moderate to severe intoxication should be followed up with ECG and cardiac enzyme levels, and those with impairments should be evaluated with ECHO. In the study of children with CO intoxication, Tekşam et al.(18) found low ejection fraction and left ventricular dysfunction in ECHO without abnormalities in ECG in $33 \%$ of patients with elevated cardiac enzymes. Troponin is a commonly known biomarker that specifically 
demonstrates myocardial damage. Marchewka et al.(34) found that troponin levels were associated with the degree of $\mathrm{CO}$ intoxication and that troponin level monitoring was useful in predicting the clinical severity and effects of CO intoxication. In our study, we determined that Troponin-I and CK-MB were reliable in predicting cardiac involvement.

The lactate level may be useful in predicting the severity of CO intoxication. In the study of Damlapinar et al.(23), $27.1 \%$ value of $\mathrm{COHb}$ showed a sensitivity of $70.5 \%$ and a specificity of 59.6 while the lactate value of $3.85 \mathrm{mmol} / \mathrm{L}$ was found to have $52.6 \%$ of sensitivity and $85.7 \%$ specificity. The positive and negative predictive values for $27.1 \% \mathrm{COHb}$ and lactate value of $3.85 \mathrm{mmol} / \mathrm{L}$ were reported to be $80 \%$, $62.5 \%$ and $50 \%, 70.9 \%$, respectively. There was no study on the predictivity of $\mathrm{COHb}$ and lactate values in cardiac involvement by ROC curve analysis. In our study, the sensitivity and specificity values of $\mathrm{COHb} 20.1 \%$ were $50.0 \%$ and $72.4 \%$, respectively; and for the lactate value of $2.95 \mathrm{mmol} / \mathrm{L}$ the sensitivity was $41.2 \%$, and specificity was $82.4 \%$, and positive and negative predictive values for these values were $41.3 \%, 78.9 \%$ and $47.3 \%, 78.2 \%$, respectively. High specificity and a negative predictive value of $2.95 \mathrm{mmol} / \mathrm{L}$ lactate can be a stimulant to demonstrate cardiac involvement in carbon monoxide poisoning.

There are some limitations to our study. The most significant limitations are the retrospective and singlecenter study design. We did not know how long the patients were exposed to carbon monoxide. Some patients had received oxygen therapy in another center and were referred to our hospital from other centers. Also, the number of patients who underwent the ECHO was low. Other limitations of the study are the low number of cases with severe carbon monoxide poisoning, and BNP levels were only present in patients who had hypotension and a Glasgow coma score of 14 or less.

In conclusion, the two most important parameters providing information about the severity of carbon monoxide intoxication are altered state of consciousness and cardiac involvement. High BNP levels may be useful in determining the severity of intoxication in patients with altered state of consciousness. We think that cardiac enzyme levels may be useful in patients with neurological symptoms and hypotension.

Conflict of Interest: No conflict of interest was declared by the authors.

Financial Disclosure: No

\section{References}

1. Davutoglu V, Gunay N, Kocoglu H, Gunay NE, Yildirim C, Cavdar M, et al. Serum levels of NTProBNP as an early cardiac marker of carbon monoxide poisoning. Inhal Toxicol. 2006;18(2):155-8.

2. Asim K, Ozlem B, Gokhan E, Zihni Y, Deniz O, Mahmut T, et al. The Use of Cerebral Oximetry in Acute Carbon Monoxide Intoxication: A Preliminary Study. Keio J Med. 2015;64(4):57-61.

3. Boztepe H, Yalaki Z, Bilge YD. Evaluation of neurological and cardiological findings in carbonmonoxide poisoning in children. Turk pediatri arsivi. 2014;49(4):314-22.

4. Hampson NB, Piantadosi CA, Thom SR, Weaver LK. Practice recommendations in the diagnosis, management, and prevention of carbon monoxide poisoning. American journal of respiratory and critical care medicine. 2012;186(11):1095-101.

5. Hampson NB. U.S. Mortality Due to Carbon Monoxide Poisoning, 1999-2014. Accidental and Intentional Deaths. Ann Am Thorac Soc. 2016;13(10):1768-74.

6. Rose JJ, Wang L, Xu Q, McTiernan CF, Shiva S, Tejero J, et al. Carbon Monoxide Poisoning: Pathogenesis, Management, and Future Directions of Therapy. American journal of respiratory and critical care medicine. 2017;195(5):596-606.

7. Yarar C. Neurological Effects of Acute Carbon Monoxide Poisoning in Children. Journal of Pediatric Sciences 2009;1:e2.

8. Besli GE, Ergüven M, Karadoğan M, Yılmaz Ö. Çocuklarda Karbon Monoksit Zehirlenmesi. JAEM. 2010;9:26-30. 
9. Moon JM, Chun BJ, Shin MH, Lee SD. Serum N-terminal proBNP, not troponin I, at presentation predicts long-term neurologic outcome in acute charcoal-burning carbon monoxide intoxication. Clinical toxicology (Philadelphia, Pa). 2018;56(6):412-20.

10. Kao LW, Nanagas KA. Toxicity associated with carbon monoxide. Clinics in laboratory medicine. 2006;26(1):99-125.

11. Zou JF, Guo Q, Shao H, Li B, Du Y, Liu M, et al. Lack of pupil reflex and loss of consciousness predict 30-day neurological sequelae in patients with carbon monoxide poisoning. PloS one. 2015;10(3):e0119126.

12. Satran D, Henry CR, Adkinson C, Nicholson CI, Bracha Y, Henry TD. Cardiovascular manifestations of moderate to severe carbon monoxide poisoning. Journal of the American College of Cardiology. 2005;45(9):1513-6.

13. Baum CR. What's New in Pediatric Carbon Monoxide Poisoning? Clinical Pediatric Emergency Medicine. 2008;9(1):43-6.

14. Kurt F, Bektas O, Kalkan G, Oncel MY, Yakut HI, Kocabas CN. Does age affect presenting symptoms in children with carbon monoxide poisoning? Pediatric emergency care. 2013;29(8):916-21.

15. Yurtseven S, Arslan A, Eryigit U, Gunaydin M, Tatli O, Ozsahin F, et al. Analysis of patients presenting to the emergency department with carbon monoxide intoxication. Turkish journal of emergency medicine. 2015;15(4):159-62.

16. Kandiş H, Katırcı Y, Karapolat B. Karbonmonoksit Zehirlenmesi. Düzce Üniversitesi Tıp Fakültesi Dergisi. 2009;11:54-60.

17. Cho CH, Chiu NC, Ho CS, Peng CC. Carbon monoxide poisoning in children. Pediatrics and neonatology. 2008;49(4):121-5.

18. Teksam O, Gumus P, Bayrakci B, Erdogan I, Kale G. Acute cardiac effects of carbon monoxide poisoning in children. European journal of emergency medicine : official journal of the European Society for Emergency Medicine. 2010;17(4):192-6.

19. Keles A, Demircan A, Kurtoglu G. Carbon monoxide poisoning: how many patients do we miss? European journal of emergency medicine : official journal of the European Society for Emergency Medicine. 2008;15(3):154-7.

20. Sokal JA, Kralkowska E. The relationship between exposure duration, carboxyhemoglobin, blood glucose, pyruvate and lactate and the severity of intoxication in 39 cases of acute carbon monoxide poisoning in man. Archives of toxicology. 1985;57(3):196-9.

21. Sokal JA. The effect of exposure duration on the blood level of glucose, pyruvate and lactate in acute carbon monoxide intoxication in man. Journal of applied toxicology : JAT. 1985;5(6):3957.

22. Buehler JH, Berns AS, Webster JR, Addington WW, Cugell DW. Lactic acidosis from carboxyhemoglobinemia after smoke inhalation. Annals of internal medicine. 1975;82(6):803-5.

23. Damlapinar R, Arikan FI, Sahin S, Dallar Y. Lactate Level Is More Significant Than Carboxihemoglobin Level in Determining Prognosis of Carbon Monoxide Intoxication of Childhood. Pediatric emergency care. 2016;32(6):377-83.

24. Phin N. Carbon monoxide poisoning (acute). Clinical evidence. 2005(13):1732-43. 
25. Aslan Ş, Erol MK, Karcıŏlu Ö, et al. . Karbon monoksit zehirlenmeli hastalarda iskemik miyokardiyal hasarın araştırılmasi. Anadolu Kardiyol Derg. 2005;5:189-93.

26. Martin JD, Osterhaudt K, Thom SR. Recognition and management of carbon monoxide poisoning in children. Clin Pediatr Emerg Med. 2000;1:244-50.

27. Gerber IL, Stewart RA, Legget ME, West TM, French RL, Sutton TM, et al. Increased plasma natriuretic peptide levels reflect symptom onset in aortic stenosis. Circulation. 2003;107(14):1884-90.

28. Seino Y, Ogawa A, Yamashita T, Fukushima M, Ogata K, Fukumoto H, et al. Application of NTproBNP and BNP measurements in cardiac care: a more discerning marker for the detection and evaluation of heart failure. European journal of heart failure. 2004;6(3):295-300.

29. Heinonen I, Luotolahti M, Vuolteenaho O, Nikinmaa M, Saraste A, Hartiala J, et al. Circulating $\mathrm{N}$-terminal brain natriuretic peptide and cardiac function in response to acute systemic hypoxia in healthy humans. Journal of translational medicine. 2014;12:189.

30. Cervellin G, Comelli I, Rastelli G, Picanza A, Lippi G. Initial blood lactate correlates with carboxyhemoglobin and clinical severity in carbon monoxide poisoned patients. Clinical biochemistry. 2014;47(18):298-301.

31. Gandini C, Castoldi AF, Candura SM, Priori S, Locatelli C, Butera R, et al. Cardiac damage in pediatric carbon monoxide poisoning. Journal of toxicology Clinical toxicology. 2001;39(1):4551.

32. Penney DG. Acute carbon monoxide poisoning: animal models: a review. Toxicology. 1990;62(2):123-60.

33. Meert KL, Heidemann SM, Sarnaik AP. Outcome of children with carbon monoxide poisoning treated with normobaric oxygen. The Journal of trauma. 1998;44(1):149-54.

34. Marchewka J, Gawlik I, Debski G, Popiolek L, Marchewka W, Hydzik P. Cardiological aspects of carbon monoxide poisoning. Folia medica Cracoviensia. 2017;57(1):75-85. 